\title{
Cenpestao
}

\section{Ressignificação da memória da cidade do Recife nas letras de frevo do maestro Nelson Ferreira}

\author{
Renata Jeane de Santana \\ Mestra; Universidade Federal de Pernambuco, Recife, PE, Brasil; \\ renatinhasantana@gmail.com \\ Fabio Assis Pinho \\ Doutor; Universidade Federal de Pernambuco, Recife, PE, Brasil; \\ fabiopinho@ufpe.br
}

\begin{abstract}
Resumo: O tema deste artigo aborda as letras de frevo como documento e sua relação com a memória social e afetiva; por isso, trata-se de uma pesquisa de caráter exploratório e documental cujo objetivo principal foi considerar, a partir das letras de frevo do maestro pernambucano Nelson Ferreira, a relevância da informação musical para a reconstituição da memória da cidade do Recife. Para tanto, estabeleceu-se como corpus as letras de frevo-canção e frevo de bloco do músico, gravadas nas duas coletâneas da extinta fábrica de discos Rozenblit: $O$ que eu fiz e você gostou... de 1959 e O que faltou e você pediu... de 1968, adotando como método a avaliação qualitativa da Análise de Conteúdo. Assim, os 39 frevos demonstraram, por meio de quatro categorias temáticas, que as letras são um produto de seu tempo, mas que também são um produto do olhar e da experiência de um homem em sua época, a qual, a partir do fenômeno da reprodutibilidade da informação, foi então massificada e perpetuada por quase 100 anos, repetindo-se por meio das narrativas das canções que, ao serem tocadas, ativam essa memória, trazendo-a para o presente e diluindo a memória individual de cada um, criando vínculos sonoros.
\end{abstract}

Palavras-chave: Ciência da Informação. Memória social. Memória afetiva. Lugar de memória. Frevo.

\section{Introdução}

No carnaval de 1977, a loja de tecidos e confecções pernambucana Casas José Araújo estreava nas rádios e televisões da época mais uma propaganda para aquele período momesco. A chamada, no entanto, não exibia os produtos da loja com seus tecidos coloridos, como era de costume, mas um frevo-canção acompanhado de um vocativo que viria a se tornar conhecido até os dias de hoje: o escuta, Nelson, o teu frevo está no ar. A canção registrava não somente 
a morte do maestro Nelson Ferreira, em dezembro de 1976, mas também a permanência expressiva de suas letras e melodias no imaginário popular daqueles tempos, algo que se apresenta até os dias atuais.

A homenagem não era sem motivo. Nelson Ferreira tinha partido depois de deixar um extenso legado à cultura brasileira, por meio de sua carreira como compositor, músico, diretor musical e maestro de orquestras, acompanhando e registrando as transformações urbanas e culturais de sua época em suas letras e canções - um papel que acabou lhe conferindo o título de o dono da música. Assim, após mais de 40 anos de sua morte, as composições do maestro Nelson Ferreira, sobretudo os frevos, nunca deixaram de ser reproduzidas, tendo alcançado inclusive as várias gerações que vieram depois, como que confirmando o prenúncio do famoso jingle que anunciava: o teu frevo está no ar.

Dessa forma, a reprodução amiúde das letras de frevo do maestro, sempre no ar, é também a reprodução das narrativas construídas por Nelson, contando e recontando aquilo que o músico procurou registrar em sua época e cuja execução massiva não somente impediu o apagamento, como acabou por diluir essas narrativas nas chamadas memória coletiva, social e afetiva da cidade do Recife, demonstrando, com isso, o caráter documental da informação musical.

Contudo, atestar dentro da Ciência da Informação (CI) que essas músicas se transformaram em documentos e relacioná-las a lugares de memória nos levaram a uma problemática de pesquisa. Visto que, de acordo com Café e Barros (2016) e Bezerra et al. (2016), ainda são incipientes os estudos em CI que relacionem a informação musical e a memória, sobretudo com um olhar menos pragmático e mais humanístico.

Para tanto, a problemática de pesquisa que orienta este trabalho resulta na seguinte indagação: é possível considerar a informação musical, que constitui as letras dos frevos do maestro pernambucano Nelson Ferreira, relevante para a reconstituição da memória da cidade do Recife?

A presente pesquisa justifica-se por proporcionar um aprofundamento teórico para permitir contribuições à área de conhecimento da CI, ampliando os estudos que relacionem a informação musical como documento e memória. 


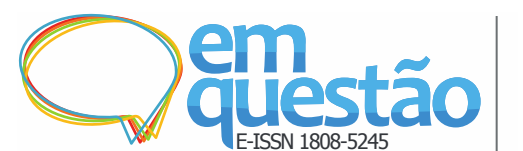

Ressignificação da memória da cidade do Recife em letras de frevo do maestro Nelson Ferreira

Renata Jeane de Santana e Fabio Assis Pinho

Além disso, acaba também por valorizar o papel dos registros fonográficos e ainda por revisitar a obra do maestro Nelson Ferreira, ou, de outro modo, demonstrar que é a obra do maestro que nos revisita.

Nesse sentido, esta pesquisa tem como objetivo geral: considerar, a partir das letras de frevo do maestro Nelson Ferreira, a relevância da informação musical para a reconstituição da memória da cidade do Recife.

\section{O documento no compasso da Ciência da Informação}

Como um passo de dança que rodopia sobre o próprio eixo, em que o corpo se desloca em diferentes direções, inclusive em torno de outros eixos mais ou menos dispostos, movimenta-se o conceito de documento na CI. À luz dessa dança caleidoscópica, aquilo que gira, em qualquer rotação que seja, recolhe cacos e redesenha assertivas, embora dentro de um contínuo pulsante. O compasso que se apresenta neste artigo recorre à coreografia invisível inscrita pela - e para - noção de documento na sociedade moderna, buscando encontrar, nos timbres e nos gestos, o salto que sustente a posição dos objetos não convencionais como documento, como é o caso da informação musical.

É certo que a música é íntima da humanidade há muito mais tempo que a noção de documento - essa que nos cerca hoje e com a qual nos acostumamos, ao menos em suas características mais simples. No entanto, a noção de que a música, como som e palavra cantada, configura-se também como documento, podendo assim subsidiar estudos sobre a memória, é uma validação recente na CI, o que revela uma noção própria do amadurecimento dessa disciplina no século XX. Sendo, a CI personagem do percurso em que a modernidade cliva o entendimento sobre a sua própria expansão informacional, seus desdobramentos, práticas e subjetivações.

As percepções em torno do que se configura documento inauguram a modernidade naquele crepúsculo entre a passagem dos séculos XIX e XX, na Europa de Paul Otlet. A clássica concepção de Otlet e La Fontaine sustenta importantes dimensões sobre o documento, ainda que eivada pelo pensamento positivista e, embora ingênua, em sua missão de universalizar o conhecimento por meio da alteridade (mal sabia que viriam duas Guerras Mundiais). 
Ainda assim, Otlet descortina e revela a potência que repousa nos objetos, a partir do momento em que sinaliza para o século XX que tudo pode se tornar um documento. Ora, se todo objeto é um documento em potencial, então já não interessaria tanto definir o que é um documento, mas sim, o que faz um documento (FOUCAULT, 2014; SALDANHA, 2013), ou, antes, como se torna um documento (FROHMANN, 2008), seja para obter informação, seja para obter informação sobre a informação. No entanto, concordamos com MartínezComeche (2000) quando alega que tudo pode ser um documento, como bem colocaram Otlet (2018) e Briet (1951); porém, nada é documento até ser considerado como tal, estabelecendo assim uma dialética que agita e repousa as coisas em seus processos contínuos de significação.

Destarte, importa então a chamada Informatividade de Frohmann (2008), ou seja, os fatores que devem ser levados em conta na caracterização de um documento: como atuam suas práticas sociais, suas representações, quem o descortina e depois faz uso, a quem alimenta, sob qual autoridade, se coletivo ou periférico. Briet (1951, p. 7, tradução nossa) menciona que: “[...] concreto ou simbólico, preservado ou registrado para fins de representação, de reconstituição ou de prova de um fenômeno físico ou intelectual".

São essas as inferências que buscam fazer os chamados neodocumentalistas, quando da retomada dos estudos Otletianos no período pósguerra (BUCKLAND, 1991; SALDANHA, 2013), as quais sediam e interessam à investigação desta pesquisa.

À revelia dos aspectos excessivamente morfológicos, mas buscando retomar uma leitura mais ampla sobre o documento, encontramos, nos últimos 40 anos, uma linha do tempo com valorosas contribuições nesse sentido, bem como o amadurecimento de um campo disciplinar específico para esses olhares, afinal, nas palavras de Rabello (2011), é na CI que o conceito de documento é configurado a uma categoria.

Ainda segundo Rabello (2011, p. 20): “[...] todo conceito ao assumir a condição de categoria adquirirá também uma dimensão abstrata e transcendente capaz de sintetizar 'em si' diferentes fenômenos e de ajudar a explicá-los”. E isso, vale lembrar, tanto dentro da CI quanto no embate conceitual interdisciplinar no qual a categoria foi e é exposta. Destarte, as noções de 
documento na CI e nas disciplinas que se avizinharam não perderam de vista os fundamentos Otletianos e se desenvolveram semelhante à definição de Capurro e Hjorland (2007), cuja argumentação afirma que a história de um conceito vai crescendo de modo consoante a sua teoria.

Dessa forma, o efeito pós-Segunda Guerra aduziu à continuidade dos estudos acerca do documento. A própria reformulação do conceito, desenvolvido por Suzanne Briet nos anos 50, pode ser considerada mais completa do que o seu primeiro ensaio, ainda na década de 30, visto a bem recebida inclusão dos aspectos simbólicos e intelectuais. Para Escarpit (1976), o documento é um meio de constituição do saber que, porém, não é mais restrito à linearidade dos eventos. Essa definição torna-se interessante à medida que ilustra a independência interna da mensagem como algo que rompe, inclusive, com as antigas visões que contemplavam o é documento em detrimento do vir a ser, uma vez que somos simultâneos ao documento e ele nos cerca. Embora concordemos com a visão pragmática de Estivals (1978), esse objeto somente torna-se documento quando encontra o seu usuário.

É por conta disso que Meyriat (1981, p. 241, tradução nossa) nos acrescenta que o conceito de documento "[...] não se impõe como uma evidência inicial, ele depende de pontos de vista [...]". Sagredo Fernández e Izquierdo Arroyo (1982) também reforçam as ideias de Estivals (1978) e Meyriat (1981) na medida em que enfatizam a importância do papel, tanto do contexto quanto do uso/usuário, embora, como lembra Hayles (2003 ${ }^{1}$ apud LUND, 2009), seja possível que o documento venha a ter um significado distinto para cada usuário e, devido à sua permanência, uma variedade de usos também.

Percebe-se, então, que tanto a recepção quanto o contexto são imprescindíveis para esses estudos (LUND, 2009), pois ambos os elementos podem estar envolvidos no processo de elaboração do documento e na sua validação, uma vez que tudo se realiza em sociedade. Tanto que, na percepção de Capurro e Hjorland (2007), é irrelevante esmiuçar-se em cima da primeira essência do objeto, já que o porquê do seu valor de documento só é validado à medida que assume valor informativo para uma coletividade ou domínio. Buckland (1991) pode concordar com esse aspecto a partir da sua definição de 


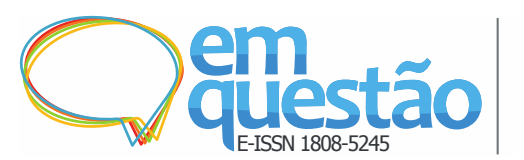

Ressignificação da memória da cidade do Recife em letras de frevo do maestro Nelson Ferreira

Renata Jeane de Santana e Fabio Assis Pinho

informação como coisa, já que alarga as possibilidades das propriedades informativas.

Ante esse vir a ser documento, algumas questões emergem simultaneamente, como as propriedades conteudísticas e também morfológicas. De acordo com Ortega e Lara (2010, p. 378):

\footnotetext{
“[...] por representar o registro (instância física) e a informação (instância simbólica), o termo 'documento' melhor caracteriza os diversos tipos de informações, registradas em qualquer suporte, e abordadas segundo os mais variados contextos de produção e uso".
}

Para Meyriat (1981), essas dimensões de natureza material (o objeto que serve de suporte) e conceitual (o conteúdo, a informação) operam de forma conjunta e inseparável uma da outra, sendo assim uma entidade de duas faces, como um signo. Nesse sentido, Lara e Ortega (2011, p. 382) destacam que “[...] as características do signo permitem confirmar que o documento é uma construção, uma leitura do 'real' sob determinada perspectiva." Ao que podemos resgatar, para esse sentido de determinada perspectiva, a noção de Prática Documentária de Frohmann (2008), pela qual o autor estabelece uma perspectiva relacional do documento para demonstrar as relações entre a sociedade e os documentos nela produzidos.

Assim, dentre as propriedades que marcam o caráter relacional dos documentos, segundo Frohmann (2008) - (1) as relações institucionais, (2) a disciplina social, (3) a historicidade, e (4) a materialidade -, vamos destacar aqui a materialidade, visto que, para o autor, é a materialidade documental que estabelece as práticas documentárias. Segundo Frohmann (2008), estudar a documentação é estudar as consequências e os efeitos da materialidade da informação ou, em outras palavras, os efeitos do documento.

Contudo, a materialidade em Frohmann (2008), de sentido foucaultiano, não se confunde com o aspecto físico do documento, mas antes aproveita as ideias de peso, massa, inércia, resistência e estabilidade de Foucault quando se refere à materialidade dos enunciados. Ao transpor a compreensão foucaultiana para o documento na CI, Frohmann (2008) não somente objetiva investigar as fontes de poder na sociedade que vão garantir massa e peso aos documentos 
(bem como a resistência às mudanças), como acaba por resvalar em uma axial dicotomia para a CI, a materialidade versus a imaterialidade.

Bem, se todo conteúdo documental pode apresentar materialidade, podemos afirmar, nos termos de Frohmann, que o imaterial também possui a sua materialidade. Nesse sentido, afiançamos que alguns tipos de documentos podem ser classificados como tangíveis e intangíveis e ainda apresentarem materialidade (OCAMPO, $1991^{2}$ apud DODEBEI, 2011, p. 3).

Particularmente, a música, enquanto documento, interessa-nos aqui por seu caráter efetivamente simbólico e, ao mesmo tempo, intangível (o som), material (no sentido foucaultiano trazido por Frohmann, o peso das letras das canções), tangível (o suporte, como o disco, o CD, a partitura), imaterial (como indicador cultural) e, simultaneamente, potencialmente informativa, subjetiva, produto social e cultural que preserva a memória social (ROJAS, 2005).

Como nos acrescenta Dodebei (2011, p. 4):

[...] todo suporte material da informação deve ser revisto, uma vez que não encontraremos seu sentido e seu significado tomando, apenas, sua forma e seu potencial informativo, sem considerar a interlocução e, mais especificamente, a intenção de preservação no âmbito da memória social.

Contudo, a noção de informação musical como documento ainda é um aspecto pouco explorado na Ciência da Informação (CAFÉ; BARROS, 2016; BEZERRA et al., 2016), fazendo parte do que Bezerra e outros (2016) agruparam no termo "objetos não convencionais da CI".

Nesse sentido, Morigi e Bonotto (2004) afirmam que a informação musical, ao expressar os sentimentos coletivos por meio de uma linguagem poética e metafórica, faz parte da história e da cultura de um povo, ou seja, sem o aspecto coletivo, social e cultural, não podemos investigar a informação musical.

Porém, outra compreensão sobre esse objeto também nos é interessante à revelia de uma possível dicotomização excessiva entre os elementos objetivos versus subjetivos, ou ainda material versus imaterial, entendendo, pois, que todos esses elementos podem se apresentar em um mesmo objeto, mudando apenas suas posições - como em um girar de um caleidoscópio. 


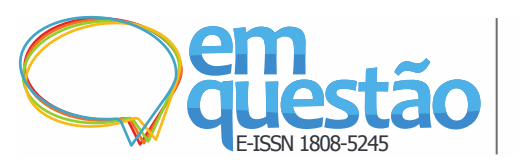

Ressignificação da memória da cidade do Recife em letras de frevo do maestro Nelson Ferreira

Renata Jeane de Santana e Fabio Assis Pinho

Dito isso, podemos prosseguir entendendo que a informação musical como recurso informacional registrado, portanto, um documento - não pode ser isolada em seus atributos e contextos, pois como nos complementa Café e Barros (2016), a segmentação dos elementos de uma música não é uma estratégia eficiente, uma vez que sua significação ocorre somente quando da relação de todos os elementos, incluindo aqueles estruturais, culturais, subjetivos.

Assim, entendemos que o conjunto desses elementos na informação musical não somente vai expandi-la como documento e uma possível fonte histórica, mas também - e concomitantemente - poderá funcionar como processo de reconstrução da memória coletiva, por meio de narrativas apresentadas pelas letras e pelo contexto de seu autor, desenhando paisagens invisíveis por meio de sua reprodutibilidade e permanecendo no imaginário afetivo e social (MAFFESOLI, 1998; MORIGI; ROCHA; SEMENSATTO, 2012).

Nesse sentido, não podemos falar de informação musical como documento e possível reconstituidor da memória no âmbito urbano, como propõe este trabalho, sem adentrarmos pelas veredas das chamadas memória social e coletiva no espaço citadino, esse espaço polifônico e palimpséstico onde o contar e o recontar, o lembrar e o esquecer, estão imbricados com as trajetórias pessoais dos indivíduos.

\section{A memória e seus lugares}

Massoni et al. (2017) sustentam que podemos pensar a memória social como "[...] um organismo vivo, formado por diferentes grupos e dinâmicas sociais, que têm a cidade como um dos pontos de contato e rememoração." (MASSONI et al., 2017, p. 148). Dessa forma, as cidades serão aqui o palco dessas relações que, nos termos de Dodebei e Storino (2007, p. 276), “[...] são espaços urbanos reais, mas são, sobretudo, espaços imaginados por cada um de nós na revolução criadora da nossa memória".

É na cidade que o indivíduo contemporâneo exerce cotidianamente a "memória hábito" de Bergson (1999) e é nesse mesmo espaço que o indivíduo 
acessa não somente a sua memória individual/pessoal, mas também - e sobretudo - a memória coletiva: as narrativas não somente dos seus pares de indivíduos como também da própria cidade, dos acontecimentos e personagens dessa cidade. De forma que, ao fim, as narrativas internas do indivíduo (uma festa de aniversário, o falecimento de um familiar) já estão sobremaneira imbricadas com as narrativas externas (a demolição de um casario do século XIX, a mudança da paisagem urbana, a patrimonialização de uma rua).

Desse modo, dissociar o individual do coletivo nas cidades, além de uma tarefa hercúlea, atingiria noções de pertencimento e identidade, o que resvalaria quase em uma aporia nesses termos.

Assim, Massoni et al. (2017, p. 148) colocam que "As lembranças e esquecimentos, as ruínas e locais de uma cidade podem estabelecer um diálogo próximo, bem como um silêncio distanciado, com seus habitantes." Visto que as cidades são o que Corboz (2001) chama de territórios-palimpsestos, ou seja, um lugar onde as narrativas e as paisagens são sobrepostas no tempo e no espaço, coexistindo simultaneamente o novo e os rastros, os vestígios do passado, formando um borrão de memórias.

A ideia da superposição de tempos em um mesmo espaço, que caracteriza a ideia do palimpsesto como conhecemos, encontra fundamento também no que diz Calvino (1990) ao defender que uma cidade abriga muitas outras cidades. Dessa maneira, entendemos que há a cidade como a vemos - a cidade que está desperta - e outras - ocultas, em eco, mas cujas representações e reconstituições ainda são evocadas por algumas chamadas à lembrança, alguns lugares de memória, como a informação musical, as canções populares urbanas.

Canevacci (2004) observa que esse território é palimpséstico também sonoramente. Para Canevacci (2004, p. 18), as cidades são aglomerações polifônicas, caracterizadas “[...] pela sobreposição de melodias e harmonias, ruídos e sons, regras e improvisações”. Nesse sentido, Lima Filho (2007, p. 336) completa que a cidade forma “[...] uma matéria, histórica, cultural, polissêmica que emoldura um quadro de meta narrativas, imagens, lembranças e sociabilidades". Contextualmente, o indivíduo urbano habita esse espaço e interage com ele, criando e absorvendo as informações sonoras em uma paisagem sonora. 


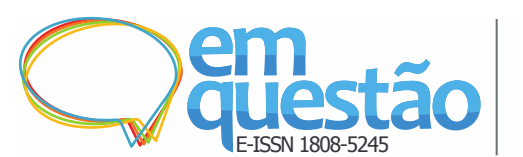

Ressignificação da memória da cidade do Recife em letras de frevo do maestro Nelson Ferreira

Renata Jeane de Santana e Fabio Assis Pinho

Observando esse viés, é até difícil isolar acusticamente a experiência humana nos centros urbanos, visto que a polifonia diária (desde sirenes, buzinas, apitos até as vinhetas de programas televisivos, radiofônicos ou som de fogos de artifício) sempre vai indicar algo e, naturalmente, inspirar sensações. Para Menezes (2016), essa experiência ruidosa nas cidades vai criar no homem uma espécie de vínculo sonoro, uma concepção de comunicação como atividade vinculadora, isto é, geradora de ambientes de afetividade.

Os vínculos sonoros são constituídos por uma complexa trama de matizes afetivos (MENEZES, 2016). Assim, estamos vinculados à nossa paisagem sonora e aos seus elementos, não somente pelo que o som nos indica (como as badaladas de um sino de igreja às 18h), mas também pelo que nos contam (e recontam) as suas narrativas, como as letras das músicas populares. Tais narrativas, ao ensejarem reconstituir o passado da cidade do Recife - por meio de sua presença efetiva e justaposição no espaço-tempo -, sua memória, seus costumes, histórias, personagens, contextos, bordões, conduzem o flâneur (aqui, os sujeitos ouvintes ou leitores) em direção a um tempo que desapareceu, mas cujas esquinas - ou dobras - da cidade-palimpsesto podemos tentar reconstituir.

Sobre isso, Maia (2005, p. 80), analisando os percursos de Michel Maffesoli, comenta, em relação à experiência compartilhada nas cidades, que:

"[...] Maffesoli mostra a nossa capacidade de produzir um 'curtocircuito' no tempo e no espaço através da comunicação. [posto que] Ocupamos um espaço material (ruas, monumentos, trânsito) e também imaterial a partir das imagens de diversas ordens."

Nesse contexto, destaca-se a cartografia simbólica do passado evocada pelas narrativas da informação musical, no caso das músicas populares urbanas.

Essa ambiguidade é demonstrada também por Freitas (2014), ao lembrar que a ambiguidade é justamente a marca central daquilo que entendemos hoje como patrimônio. Para o autor, o patrimônio, situado entre o passado e o presente, entre a história e a memória, entre o material e o imaterial, enseja uma capacidade de ser instrumento mediador entre essas várias esferas e campos. É nesse sentido que não podemos perder de vista, neste trabalho, que a música popular urbana denominada frevo - não somente letra e música, mas também o 


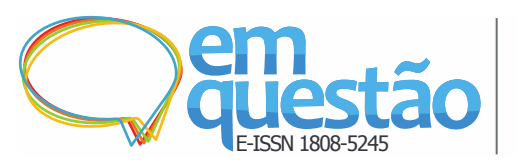

conjunto cultural contemplado nesse termo, tal como dança, coreografia, festa foi declarada, em 2012, Patrimônio Cultural Imaterial da Humanidade.

Assim, esse percurso nos permite inferir sobre essas expressões musicais e suas narrativas na cidade do Recife, e muitas vezes sobre a cidade do Recife, que elas ocupam, nos termos vistos anteriormente, uma capacidade mediadora entre o presente e o passado, o material e o imaterial, a história e a memória. Essa dimensão é observada também por Souza e Crippa (2011, p. 247) quando afiança que “[...] não faz sentido uma separação entre patrimônio tangível e intangível ou objeto e processo, pois ele só se explica nesta relação”.

Ainda segundo Souza e Crippa (2011, p. 247), uma vez constatada essa dimensão "[...] obriga qualquer ato documentário ir além da descrição dos produtos ou documentos originais de uma manifestação cultural e considerar os processos que garantiram sua produção.” É nesse sentido que Crippa (2009) alega que a discussão sobre o patrimônio documental permitiu repensarmos o conceito de documento, o que é essencial dentro das dinâmicas da CI.

Assim, em última análise, colocamos que essa informação musical, popular e urbana, o frevo - documento e patrimônio - executado/encenado amiúde, vai contar e recontar as narrativas sobre a própria cidade, como é o caso das narrativas apresentadas nas letras dos frevos do maestro Nelson Ferreira, um dos autores mais populares e influentes da história do ritmo no Brasil (SALDANHA, 2008; TELES, 2008; BELFORT, 2009). Nesse sentido, vejamos então o percurso metodológico desta pesquisa.

\section{Percurso metodológico}

Esta pesquisa caracterizou-se como qualitativa, tendo caráter exploratório e documental. Para alguns autores (GIL, 2002; CERVO; BERVIAN; SILVA, 2007), recomenda-se a pesquisa exploratória quando há pouco conhecimento sobre o problema a ser estudado. Assim, compreendemos que essa orientação está em consonância não só com a problemática apresentada anteriormente, a incipiência de trabalhos na CI que tenham investigado a informação musical para subsidiar estudos sobre a memória, mas também no tocante ao próprio universo desta pesquisa, uma vez que este é o primeiro contato mais amplo com as letras de frevo do maestro Nelson Ferreira. 
Para tanto, foi adotado o método de Análise de Conteúdo de Bardin (2009), autora amplamente discutida no Brasil e cuja argumentação teórica defende, entre outros aspectos, que alcançar os objetivos em uma pesquisa só é possível em função dos documentos disponíveis. E é por isso que este trabalho se debruçou sobre a obra do maestro Nelson Ferreira, no intuito de explorar o vasto material deixado pelo músico, a fim de, com isso, compor um corpus documental homogêneo e coerente.

A Análise de Conteúdo é relevante para pesquisas de caráter qualitativo, pois se trata de um conjunto de estratégias para compreender os sentidos do objeto a ser analisado, que neste caso são as letras de frevo (FRANCO, 1986).

O corpus da pesquisa foi composto pelas letras de frevo do maestro Nelson Ferreira, que foram gravadas em duas coletâneas: $O$ que eu fiz e você gostou... de 1959 e O que faltou e você pediu..., de 1960, ambas pela fábrica de vinil e gravadora de discos pernambucana Rozenblit.

O maestro Nelson Ferreira compôs em torno de 600 músicas entre frevos, valsas, marchinhas, polcas, jingles políticos e até canções temáticas para festas de 15 anos, apresentando, ao longo da vida, uma carreira versátil e requisitada. Contudo, tendo sido as suas composições de frevo, tanto as letradas como as instrumentais, sua obra mais expressiva e consequentemente executada até os dias de hoje, decidimos analisar a ressignificação da memória da cidade do Recife nas letras de seus frevos canção e de bloco. No entanto, percebemos que optar pela totalidade resvalaria em um problema à análise, pois nem todos os frevos escritos pelo maestro foram gravados, tendo muitos se perdido com o tempo. Assim, temos a justificativa para a escolha do corpus.

O primeiro Long Play (LP) do maestro, a coletânea $O$ que eu fiz e você gostou... de 1959 reúne 23 canções das décadas de 20, 30 e 40, ao lado do LP $O$ que faltou e você pediu... de 1968, que também teve como característica a inclusão de 24 músicas escritas em várias fases da carreira do maestro, somando assim, para este estudo, um corpus com 47 letras. Desse corpus, oito frevos presentes nas duas coletâneas eram frevos de rua, ou seja, só continham o instrumental e, por isso, foram excluídos. Portanto, foram analisadas 39 letras. As letras foram obtidas no acervo da Fundação Joaquim Nabuco (Recife, PE) e 
a cópia das capas dos LP's foram obtidas no acervo do Memorial Denis Bernardes, da Universidade Federal de Pernambuco.

Nesse sentido, após a realização da escuta de todas as faixas das coletâneas a partir de seus LP's, foi realizado o processo de transcrição dos áudios e, posteriormente, seleção das microestruturas em unidades de registro e de contexto, utilizando a Análise de Conteúdo de Bardin (2009). Dessa forma, Bardin (2009, p. 134) nos esclarece ainda que a análise de conteúdo é uma técnica que visa a revelar o que está escondido ou subentendido e que, por isso, segundo a autora, a mensagem pode ser submetida a uma ou várias dimensões de análise, posto que “[...] o estudo da mensagem poderá fornecer informações relativas ao receptor ou ao público". Para isso, a análise organizou-se em torno de três polos cronológicos definidos por Bardin (2009) como: (1) Pré-análise, (2) Exploração do material e (3) Tratamento dos resultados obtidos.

Diante disso, a pré-análise foi estabelecida por meio da audição de todas as faixas dos dois LPs citados, transcrição do conteúdo de áudio e anotação dos nomes de todas as faixas que apareciam na contracapa dos dois vinis, as possíveis informações técnicas e ano da composição.

Na exploração do material, as letras foram percorridas minuciosamente com o intuito de identificar as unidades de análise (registro, contexto) que foram isoladas, examinadas e categorizadas.

Por fim, isoladas e categorizadas as unidades de análise, na fase do tratamento dos resultados obtidos, foram examinadas as subcategorias e com isso a frequência temática dos conceitos dentro de quadros comparativos, para, a partir disso e com o suporte da pesquisa documental, interpretarmos e estabelecermos as conexões entre os resultados, ou seja, as categorias foram conectadas com publicações exógenas a fim de contextualizá-las com a memória da cidade.

A seguir, temos dois exemplos de cada LP e de como se configuraram as análises. 


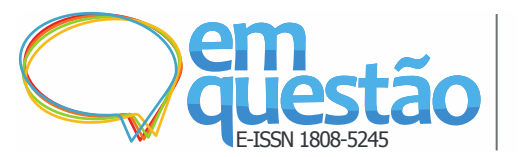

Ressignificação da memória da cidade do Recife em letras de frevo do maestro Nelson Ferreira

Renata Jeane de Santana e Fabio Assis Pinho

Figura 1- Capa do LP O que eu fiz e você gostou... de 1959.

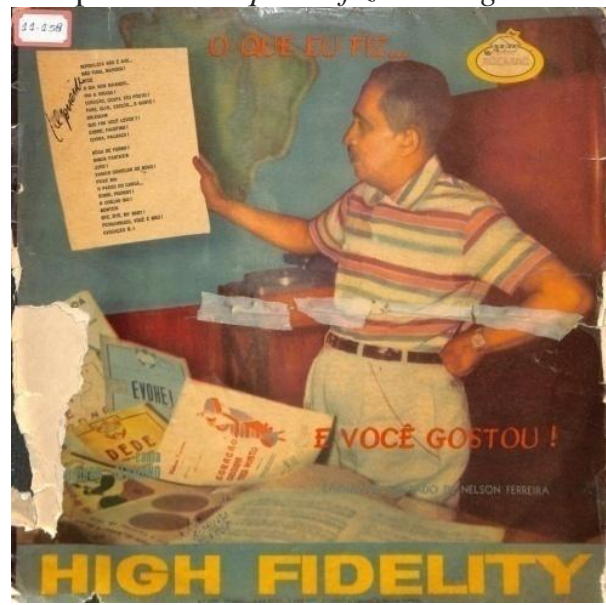

Fonte: Universidade Federal de Pernambuco (2019).

Quadro 1 - Exemplo de identificação das microestruturas nas letras do LP O que eu fiz e você gostou..., de Nelson Ferreira.

\begin{tabular}{|c|c|c|c|}
\hline $\mathbf{N}^{\mathbf{0}}$ & Música & Letra & Microestrutura \\
\hline 1 & $\begin{array}{l}\text { Borboleta } \\
\text { não é ave } \\
\text { Ano: } 1923\end{array}$ & $\begin{array}{l}\text { Borboleta não é ave / borboleta ave é / } \\
\text { borboleta só é ave na cabeça da muié / } \\
\text { borboleta, borboleta / de voar nunca se } \\
\text { cansa / menina de perna fina / de socó } \\
\text { tem semelhança / borboleta quando fores } \\
\text { / lá pras bandas do Norte / da coruja } \\
\text { minha sogra / leva o gênio de má sorte... }\end{array}$ & $\begin{array}{l}\text { Borboleta, ave, muié, } \\
\text { menina, perna fina, socó, } \\
\text { norte, coruja, sogra, gênio, } \\
\text { má sorte }\end{array}$ \\
\hline 2 & $\begin{array}{l}\text { Não puxa } \\
\text { Maroca } \\
\text { Ano: } 1929\end{array}$ & $\begin{array}{l}\text { Maroca o teu gato é um bicho gaiato / é } \\
\text { um bicho bonito / é um bicho bonito / tu } \\
\text { puxas Maroca no rabo / mas olha o diabo } \\
\text { / que rabo de gato não é pirulito / Maroca } \\
\text { o teu ganso / é um bicho até manso /que } \\
\text { nunca estrebucha / tu puxa Maroca o } \\
\text { pescoço / mas mesmo sem osso / pescoço } \\
\text { de ganso não é puxa puxa }\end{array}$ & $\begin{array}{l}\text { Maroca, gato, bicho, } \\
\text { gaiato, bonito, rabo, diabo, } \\
\text { pirulito, ganso, estrebucha, } \\
\text { puxa puxa }\end{array}$ \\
\hline
\end{tabular}

Fonte: Elaborado pelos autores.

Figura 2 - Capa do LP O que faltou e você pediu... de 1968.

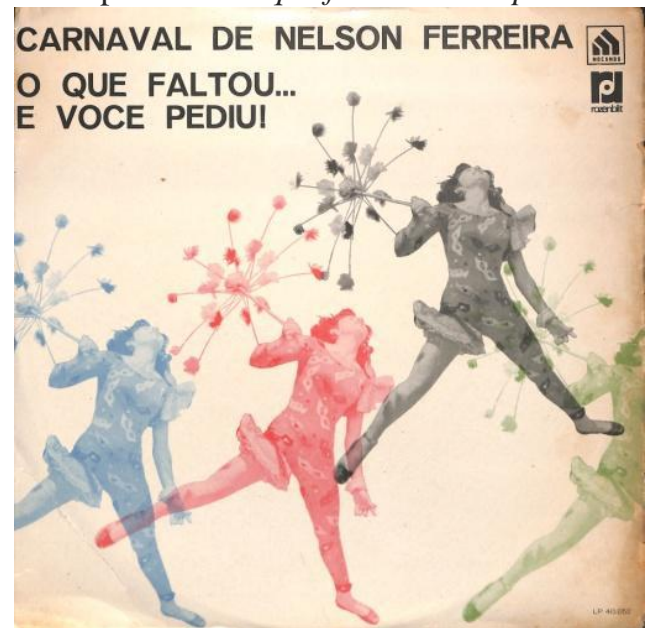

Fonte: Universidade Federal de Pernambuco (2019). 
Quadro 2 - Exemplo de identificação das microestruturas nas letras do LP O que faltou e você

\begin{tabular}{|c|c|c|c|}
\hline $\mathbf{N}^{\mathbf{0}}$ & Música & Letra & Microestrutura \\
\hline 1 & $\begin{array}{l}\text { "Cavalo do } \\
\text { cão" não é } \\
\text { "reoplano" } \\
\text { Ano: } 1961\end{array}$ & $\begin{array}{l}\text { Voadô qui vôa tanto / é homem de } \\
\text { devoção / pruquê vai perto dos santo / } \\
\text { anda aqui e em todo canto e faz das tripa } \\
\text { coração / mas quem foi que dixe prá } \\
\text { mostrá ser puritano / que tomate é } \\
\text { maxixe e cavalo do cão não é } \\
\text { "reoplano"? / um passeio nas altura além } \\
\text { dos cimo e das serra / quer seja na } \\
\text { "Saca...dura", ou num pinto de bravura é } \\
\text { coisa que a gente aterra. } \\
\text { Mais quem foi que dixe etc / quem vôa } \\
\text { muito se arrisca, pois se atira contra a } \\
\text { morte "Banca" a piaba na isca ou mostra } \\
\text { ser bôa fisca ou então é bicho forte. } \\
\text { Mais quem foi que dixe }\end{array}$ & $\begin{array}{l}\text { Voadô, vôa, homem de } \\
\text { devoção, santo, puritano, } \\
\text { tomate, maxixe, cavalo do } \\
\text { cão, reoplano, "Saca dura", } \\
\text { "Pinto", "aterra", piaba, }\end{array}$ \\
\hline 2 & $\begin{array}{l}\text { Veneza } \\
\text { Americana } \\
\text { Ano: } 1938\end{array}$ & $\begin{array}{l}\text { Veneza americana é Veneza americana / } \\
\text { linda terra original / } \\
\text { tudo nela se engalana / quando chegar o } \\
\text { carnaval / já o céu fantasiado tem estrelas } \\
\text { rendilhado / derramando claridade } \\
\text { cooperar para beleza essa cidade, } \\
\text { Veneza, ninho de felicidade / } \\
\text { Rio Capibaribe a rir / vai no seu curso a } \\
\text { seguir / namorando / deslumbrando / na } \\
\text { cadência majestosa da folia tão gostosa / } \\
\text { deste torrão encantado }\end{array}$ & $\begin{array}{l}\text { Veneza americana, } \\
\text { engalana, Rio Capibaribe, }\end{array}$ \\
\hline
\end{tabular}

Fonte: Elaborado pelos autores.

A partir do agrupamento das microestruturas, foram criadas quatro (4) categorias e suas respectivas subcategorias: Cenário (elementos da natureza, paisagem urbana, geográfico e animais), Personagens (gênero/faixa etária, parentesco, predicativos, nomes próprios), Costumes (carnaval, dança, fantasias, bloco/agremiações, brincadeira, lazer, comidas) e Afeto (sentimento/sensações, sentimentos com expressões locais). Então, a seguir, verificaremos o resultou da análise.

\section{Análise dos dados}

Na categoria Cenário, houve quatro subcategorias e, por meio delas, podemos enxergar o conjunto de elementos que compõe o espaço citadino onde se decorre a ação (ou parte dela), tanto no plano do real como na atmosfera metafórica da criação artística do maestro. O termo dia, por exemplo, aparece em sete canções, representando tanto a possibilidade quimérica na expressão um dia quanto o período diurno em que se ocorrem normalmente as festas de carnaval 
na cidade do Recife, festa que aparece de forma recorrente nas canções analisadas.

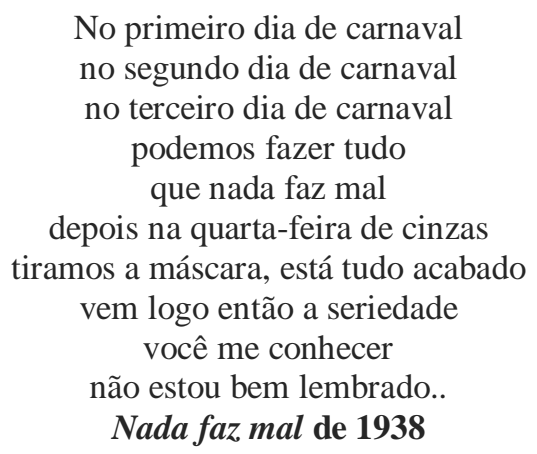

Embora constem na letra elementos importantes da paisagem urbana, como trens, bondes, arranha-chão (em ironia aos primeiros arranha-céis ou edifícios), o termo mais reincidente dessa paisagem é "rua", espaço tradicional e afetivo das ações carnavalescas e também dos encontros e desencontros do narrador, dos personagens, das passagens históricas. Um exemplo são os versos do frevo-de-bloco Carnaval da Vitória, escrito pelo maestro Nelson Ferreira e seu parceiro Sebastião Lopes em 1946, para comemorar a vitória dos aliados na Segunda Guerra Mundial, 1945, e que, mesmo tendo sido um sucesso nas rádios, só foi gravado pela Rozenblit em 1960. Dessa forma, a rua, aqui, aparece como cenário ideal para este espírito de júbilo e alívio do cenário pós-guerra.

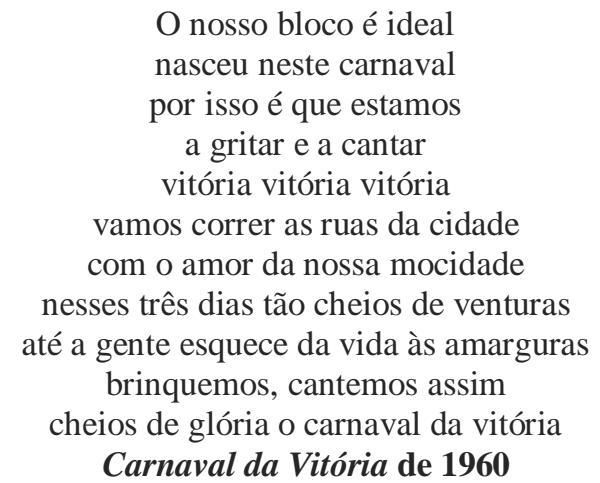

O termo mais recorrente na subcategoria geográfico é Pernambuco, constando cinco vezes nas letras e, em todas, envolvido por expressões que denotam uma certa idealização desse espaço geográfico, uma necessidade de reafirmar seus valores, como em $O$ frevo é assim de 1945, em que se menciona a origem do frevo, ou em Palhaço no passo de 1960, que se destaca que o 
carnaval de Pernambuco não possui nada igual. Nesse sentido, podemos observar o desejo de, no primeiro exemplo, reivindicar a criação do ritmo em uma forma de sobressair e exaltar o próprio Estado, e, no segundo exemplo, escrito 15 anos depois do primeiro, reforçar que, além de inventarmos o frevo, também continuamos desbancando as festas de carnaval para além de nossas barreiras geográficas - ao que, desse modo, é uma ideia um tanto bairrista (em seu absolutismo), que se percebe reverberar até os dias atuais. Podemos acompanhar essa idealização nos versos a seguir, no frevo-canção Pernambuco, você é meu, escrita em parceria com o poeta e radialista Ademar Paiva para o programa homônimo da Rádio Clube - à época, apresentado por Paiva:

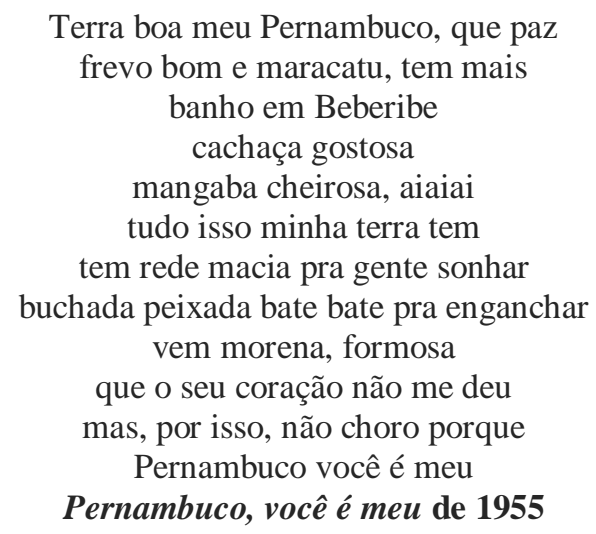

Ainda compondo o cenário, agrupamos na subcategoria denominada Animais todos os dez tipos de bichos que foram citados nas letras, pois observamos que esse dado pode ser uma referência ao cenário recifense do passado, quando, com menos edifícios e mais casas com quintais, era possível conviver com mais árvores, plantas e animais. Isso não somente nas casas particulares, mas também nos espaços públicos, como é o caso do peixe-boi, citado no frevo-canção Peixe-boi de 1940, que de fato existiu e era mantido em um tanque no Parque Amorim até a década de 70, e depois passou para a praça do Derby, sendo uma cotidiana atração da cidade do Recife até ser removido do local devido aos maus tratos da população. Nesse mesmo sentido, podemos observar a presença de gatos e gansos na letra de Não puxa, Maroca, por exemplo. 
No entanto, além de aparecerem em seu sentido real, os animais também fuguram nas letras enquanto mascotes para alguma ideia implícita, como é o caso do "touro Ferdinando" citado no frevo-canção Vamos começar de novo de 1940, que diz "vamos começar de novo, meu povo, Momo voltou a reinar, até o touro Ferdinando, tão brando, no frevo também quer entrar". O touro em questão é uma referência ao curta-metragem O Touro Ferdinando de 1938, realizado pela Walt Disney Pictures, um desenho que, à época, fez grande sucesso, faturando inclusive o Oscar de melhor curta-metragem de animação no ano de 1939. Na história, Ferdinando recusa-se a participar das tradicionais touradas espanholas, uma vez que prefere ficar sentado na grama sentindo o aroma das flores. No entanto, para o eu-lírico do frevo-canção, nem esse personagem, tão ameno, resistiria ao reinado de Momo na cidade do Recife e cairia no frevo.

Ainda enquanto mascotes, observemos também o frevo-canção Bemtevi.

Da categoria Personagens resultaram quatro subcategorias a partir das letras analisadas. Quanto ao gênero, observa-se que é mais comum o narrador, ou eu-lírico, referir-se ao público feminino ouvinte. Assim, vemos uma maior recorrência maior de menina, muié, mulher em relação a homem, que só aparece uma vez. Na letra de Borboleta não é ave de 1923, a primeira música carnavalesca de Pernambuco gravada, podemos incluir uma observação de gênero também, visto que, na letra da canção, conta-se uma obviedade: a borboleta não é uma espécie de ave, mas um inseto, e só a cabeça de uma mulher pra não saber:

\author{
Borboleta não é ave \\ borboleta ave é \\ borboleta só é ave \\ na cabeça da muié \\ borboleta, borboleta \\ de voar nunca se cansa \\ menina de perna fina \\ de socó tem semelhança \\ borboleta quando fores \\ lá pras bandas do norte \\ da coruja minha sogra \\ leva o gênio de má sorte
}

Borboleta não é ave de 1923 
A partir dessa mesma narrativa, podemos seguir para a subcategoria Parentesco, uma vez que a figura da sogra aparece em questão, reforçando o imaginário coletivo sobre esse familiar como sendo pessoas difíceis de lidar, ou um gênio de má sorte. Ao lado dela, somente a figura do pai aparecerá mais uma vez indicando parentesco, como nas letras de Bye bye, my baby de $1943 \mathrm{e}$ em Vamos começar de novo de 1943. Em ambas, percebe-se a figura masculina em um lugar de autoridade.

Quanto à subcategoria denominada de Predicativos, a forma "moreninha" é a mais reincidente, aparecendo tanto para descrever quanto como vocativo. Interessante analisar essa questão sob o ponto de vista étnico, posto que a mulher negra, assim colocada, não aparece em nenhuma das letras analisadas. A forma nêga chega a se apresentar na canção Corre, Faustina de 1938, mas como o que parece ser uma expressão popular. Ao que parece, ainda existe, nas letras analisadas, um tabu em relação à etnia negra, o que não é difícil de presumir, visto o ano de criação e gravação das canções.

Inclusive, o próprio maestro Nelson Ferreira era um homem negro e de cabelos crespos, mas que, no entanto, era conhecido no meio artístico como Nelson, o moreno bom, ressaltando assim a declarada dificuldade em valorizar o negro(a) como negro(a). Nesse sentido, as letras dos frevos analisados acabam por assinalar isso, pois levam ao imaginário as figuras das mulatas, morenas, caboclinhas, como se a mulher negra não existisse. No plano linguístico, destacamos ainda nesta categoria a figura do corta-jaca, expressão popular antiga que se refere à pessoa "puxa saco", como podemos ver no trecho a seguir:

\author{
[...] oia pra mim \\ não ser tão má \\ e pelo menos no carnavá \\ dá pro teu corta-jaca \\ um pouquinho desse olhar. \\ Dobradiça de 1934
}

Na última subcategoria da categoria denominada de Personagens, 15 termos foram distribuídos em torno dos nomes próprios. Desse número, apenas Maroca é citada duas vezes: como personagem principal da canção de 1929 que leva seu nome, Não puxa, Maroca, e também no título do frevo-de-rua de 1931, 


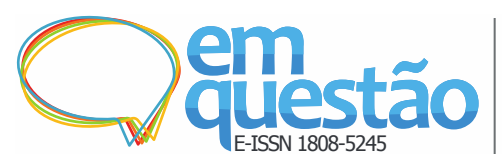

Ressignificação da memória da cidade do Recife em letras de frevo do maestro Nelson Ferreira

Renata Jeane de Santana e Fabio Assis Pinho

Maroca só qué "seu” Freitas, como podemos ver nos versos a seguir, em que a personagem Maroca aparece envolta a um cenário lúdico:

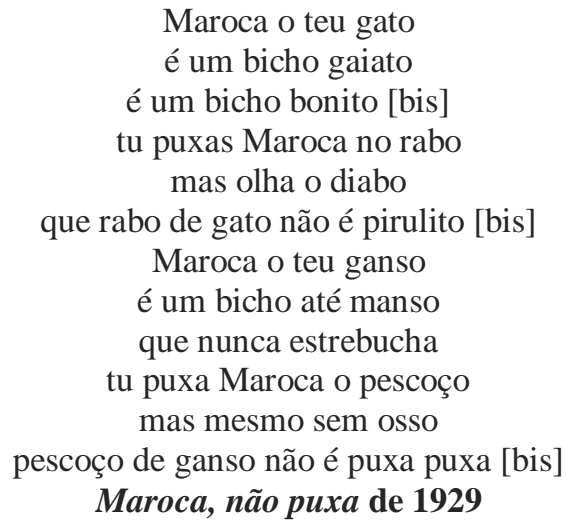

Outros personagens que registramos aqui são os cinco homens citados na canção Evocação $n^{\circ}$ l. Esse frevo-canção, considerado o maior sucesso nacional de Nelson Ferreira (BELFORT, 2009; TELES, 2008), foi escrito pelo maestro em 1955, com o objetivo de prestar uma homenagem aos antigos blocos, personagens e foliões que o maestro conhecera na década de 20, no Recife, mas que sumiram com o tempo. Dessa forma, Nelson lista nomes ilustres em sua memória, mas esquecidos do grande público, como vemos nos versos:

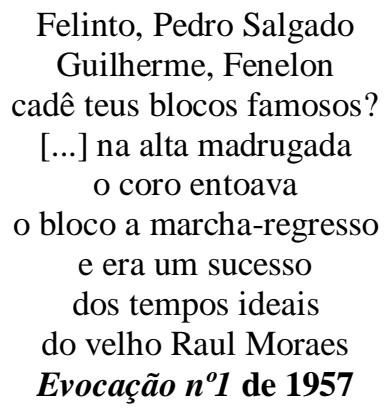

Da categoria Costumes resultaram seis subcategorias que, na maioria das vezes, aparecem envolvidas em um imaginário virtuoso de realeza, apontando a sagração dessa festa para os carnavalescos pernambucanos, como nos versos de Vamo se acabá, de 1931, que dizem "veio o Rei Momo com a deusa folia" ou ainda a letra de Coração ocupa teu posto, como podemos ver a seguir:

$$
\begin{gathered}
\text { Coração ocupa teu posto } \\
\text { elege um amor } \\
\text { que dê no meu gosto } \\
\text { com a loirinha e a moreninha }
\end{gathered}
$$




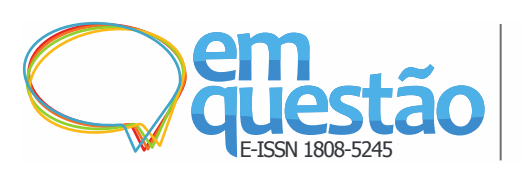

Ressignificação da memória da cidade do Recife em letras de frevo do maestro Nelson Ferreira

Renata Jeane de Santana e Fabio Assis Pinho

faz frente única com paciência estou de acordo com qualquer das duas o melhor da vida é não haver dissidência mas se preferes a monarquia e ao rei momo te escravizar integralmente, a princesa folia em qualquer dos turnos terá que arrastar

Coração ocupa teu posto de 1960

Além do Rei Momo, registra-se também na categoria denominada de Carnaval o número de blocos e agremiações carnavalescas citados nas letras de Nelson, tanto os já apresentados nos versos de Evocação $n^{\circ} 1$ quanto os da canção Corre, Faustina, que tem data de composição anterior:

$$
\begin{gathered}
\text { Ia vem vassourinhas } \\
\text { Pão duro, Ia vem Lenhadores } \\
\text { vem tudo rasgando } \\
\text { Faustinha minha nega } \\
\text { olha a onda } \\
\text { cai logo no passo } \\
\text { que eu já estou me acabando } \\
\text { Corre, Faustina de } \mathbf{1 9 3 8}
\end{gathered}
$$

Os termos referentes ao universo da dança são os mais presentes nesta categoria, rendendo 26 ao todo. As referências aparecem nas letras dando o nome oficial de passos de frevo, como tesoura e dobradiça, ou de outras danças populares, como o tango ou o samba, mas também de aspectos do próprio ato de dançar, da ação, como ponta do pé ou ioiô.

De fato, a recorrência dos nomes das danças dentro das letras pode ser vista como uma preocupação do maestro em registrar essa manifestação artística que estava surgindo em sua terra e caracterizando o carnaval nas ruas do Recife. No entanto, há duas letras que contemplam a dança e estão distribuídas aqui enquanto costume (tradição) da cidade, mas que não o são, como é o caso dos frevos-canção O passo do Caroá e Dança do carrapicho, ambos de 1942. Nesse caso, as duas letras, criadas pelo maestro em parceria com Sebastião Lopes, sugerem a existência de uma nova dança, um novo passo de frevo a ser apresentado aos ouvintes. Porém, nem Caroá e nem Carrapicho são um novo tipo de dança criado na improvisação dos passos dançantes da festa de carnaval, como procura sugerir as letras, pois ambos se referem, na verdade, ao produto de uma fábrica de tecidos. 
Da categoria denominada de Afeto resultaram duas subcategorias nas quais o amor aparece atrelado às ilusões do carnaval, relacionado aos encontros despretensiosos proporcionados pela festa, como no frevo-canção Nada faz mal de 1938. Ou ao contrário, reforçando a ideia de que é possível esquecer um amor ingrato no carnaval, como na letra do frevo-canção Arlequim de 1937.

Ainda ao que diz respeito a relações amorosas, a letra do frevo-canção de 1943, Bye bye, my baby, registra um emblema intercultural, narrando o início do processo de aculturação por meio da língua inglesa na cidade do Recife. Nesse sentido, não faltaram encontros amorosos (e iludidos) entre os americanos e as moças solteiras recifenses. Assim, acompanhamos nos versos:

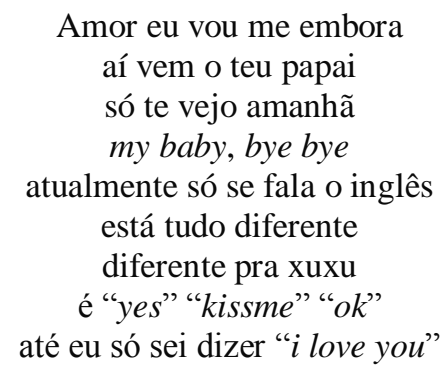

Bye bye, my baby de 1943

Para além das expressões idiomáticas estrangeiras, registram-se também os sentimentos e sensações manifestados com expressões locais, como estrebuchar, esbagaço, emborrachar.

\section{Considerações Finais}

Juntar os grãos do passado e do presente, além de uma tarefa hercúlea, pode resvalar em um trabalho de Sísifo, parece heroico, mas não é, uma vez que consome a si mesmo em seu movimento unilateral quando é preciso justamente considerar esses grãos em um movimento dialético. Afinal, sob cada pedra que a Ciência ergue, calcariza-se um dado, um lado do dado (ou somente as arestas) daquilo que um dia foi. Nesse sentido, as considerações deste trabalho não podem ser feitas sem antes nos lembrarmos disso.

No entanto, o que se percebe é que, à revelia das informações históricas e de seu caráter legalista de "prova oficial", as narrativas apresentadas pelos 39 frevos do Maestro Nelson Ferreira demonstram que as letras são um produto de seu tempo, mas que também, e principalmente, são um produto do olhar e da 
experiência de um homem em sua época. Essa experiência, a partir do fenômeno da reprodutibilidade da informação, foi então massificada e perpetuada por quase 100 anos, repetindo-se por meio das narrativas das canções que, ao serem tocadas, ativam essa memória, trazendo-a para o presente e diluindo a memória individual de cada um, criando vínculos sonoros.

O que percebemos, após a análise de todos os dados, é que as ressignificações da cidade do Recife não se dão apenas de forma descritiva, pois é perceptível a criação, a partir das letras, de uma atmosfera, de algo que quer se colocar como característico da cidade, como os sentimentos incontestáveis sobre a posse do melhor e maior carnaval, sobre a própria beleza da cidade, sobre sentimentos carnavalescos como amor, dor e saudade - informações essas que são repetidas entre diferentes gerações, diluindo-se no coletivo, ganhando notas de verdade. Nesse sentido, o objetivo geral da pesquisa foi alcançado e a resposta à indagação que este trabalho analisou traz consigo a relevância da informação musical para a reconstituição da memória da cidade do Recife, bem como sinaliza pistas e proposições para outros estudos a partir deste, no futuro. E, por enquanto, encerra-se assim: entre passado e futuro, juntando grãos, invertendo ampulhetas.

\section{Referências}

BARDIN, L. Análise de conteúdo. Lisboa: Edições 70, 2009.

BELFORT, A. Nelson Ferreira: o dono da música. Recife: Comunigraf, 2009.

BERGSON, H. Matéria e memória. São Paulo: Martins Fontes, 1999.

BEZERRA, E. M. B. L. O. et al. Música, documento e informação: a canção inscrita, os gêneros musicais e suas variantes como objeto de estudo da Ciência da Informação (CI) no Brasil no período de 1989 a 2014. In: ENCONTRO

BRASILEIRO DE BIBLIOMETRIA E CIENTOMETRIA, 5., 2016, São Paulo. Anais [...]. São Paulo: USP, 2016. p. A41.

BRIET, S. Qu'est-ce que la documentation? Paris: Édit, 1951.

BUCKLAND, M. K. Information as thing. Journal of the American Society for Information Science and Technology, New York, v. 45, n. 5, p. 351-360, 1991. 
CAFÉ, L. M. A.; BARROS, C. M. Panorama da produção nacional e internacional sobre informação musical. Informação \& Sociedade: estudos, João Pessoa, v. 26, n. 2, p. 107-119, maio/ago. 2016.

CALVINO, I. As cidades invisíveis. São Paulo: Companhia das Letras, 1990.

CANEVACCI, M. A cidade polifônica: ensaio sobre a antropologia da comunicação urbana. 2. ed. São Paulo: Studio Nobel, 2004.

CAPURRO, R.; HJORLAND, B. O conceito de informação. Perspectivas em Ciência da Informação, Belo Horizonte, v. 12, n. 1, p. 148-207, 2007.

CERVO, A. L.; BERVIAN, P. A.; SILVA, R. Metodologia científica. 6. ed. São Paulo: Pearson Prentice Hall, 2007.

CORBOZ, A. Le territoire comme palimpseste et autres essais. Paris: l'Imprimeur, 2001.

CRIPPA, G. O patrimônio cultural como documento: reflexões transdisciplinares para novos horizontes na Ciência da Informação. Transinformação, Campinas, v. 21, n. 3, p. 207-223, set./dez., 2009.

DODEBEI, V. Cultura Digital: novo sentido e significado de documento para a memória social? DataGramaZero, Rio de Janeiro, v. 12, n. 2, sem paginação, 2011.

DODEBEI, V.; STORINO, C. As cidades e o Patrimônio cultural. In: ABREU, R.; CHAGAS, M. S.; SANTOS, M. S. (org.). Museus, coleções e patrimônios: narrativas polifônicas. Rio de Janeiro: Garamond, 2007.

ESCARPIT, R. Théorie générale de l'information et de la communication. Paris: Hachette, 1976.

ESTIVALS, S. R. La bibliologie: introduction à une science de l'écrit. Paris: Société de bibliologie et schématisation, 1978.

FOUCAULT, M. A arqueologia do saber. Rio de Janeiro: Forense, 2014.

FRANCO, M. L. P. B. O que é análise de conteúdo. São Paulo: PUC, 1986.

FREITAS, M. F. Museu de cidade: entrecruzando patrimônio e cidades. Múltiplos Olhares em Ciência da Informação, Belo Horizonte, v. 4, n. 1, p. 1-8, mar. 2014.

FROHMANN, B. O caráter social, material e público da informação. In: FUJITA, M. S. L.; MARTELETO, R. M.; LARA, M. L. G. (org.). A dimensão epistemológica da Ciência da Informação e suas interfaces técnicas, políticas e institucionais nos processos de produção, acesso e disseminação da informação. São Paulo: Cultura Acadêmica, 2008. p. 17-34. 
GIL, A. C. Como elaborar projetos de pesquisa. 4. ed. São Paulo: Atlas, 2002.

LARA, M. L. G.; ORTEGA, C. D. Para uma abordagem contemporânea do documento na Ciência da Informação. In: CONGRESO ISKO, 10., 2011, Ferrol. Anais [...]. Ferrol: ISKO, 2011. p. 371-387.

LIMA FILHO, M. F. A cidade como objeto: ressonâncias patrimoniais. In: ABREU, R.; CHAGAS, M. S.; SANTOS, M. S. (org.). Museus, coleções e patrimônios: narrativas polifônicas. Rio de Janeiro: Garamond, 2007.

LUND, N. W. Document theory. Annual Review of Information Science and Technology, Medford, v. 43, n. 1, p. 339-432, 2009.

MAFFESOLI, M. Elogio da razão sensível. Rio de Janeiro: Vozes, 1998.

MAIA, J. Michel Maffesoli e a cidade partilhada. FAMECOS, Porto Alegre, v. 12, n. 26, p. 77-85, abr. 2005.

MARTÍNEZ-COMECHE, J. A. The nature and qualities of document in archives, libraries and information centres and museums. Journal of Spanish Research on Information Science, Madrid, v.1, n.1, p. 5-10, 2000.

MASSONI, L. F. H. et al. As narrativas da cidade no aplicativo Porto Alegre Guide. Informação \& Sociedade: Estudos, João Pessoa, v. 27, n. 1, p. 147-160, jan./abr. 2017.

MENEZES, J. Cultura do ouvir e ecologia da comunicação. São Paulo: Uni, 2016.

MEYRIAT, J. Document, documentation, documentologie. Schéma et Schématisation, Noyers-sur-Serein, n. 14, p. 51-63, 1981.

MORIGI, V. J.; BONOTTO, M. E. K. A narrativa musical, memória e fonte de informação afetiva. Em Questão, Porto Alegre, v. 10, n. 1, p. 143-161, jan./jun. 2004.

MORIGI, V. J.; ROCHA, C. P. V.; SEMENSATTO, S. Memória, representações sociais e cultura imaterial. Morpheus, Rio de Janeiro, v. 9, n. 14, p. 182-191, 2012.

ORTEGA, C. D.; LARA, M. L. G. A noção de documento: de Otlet aos dias de hoje. DataGramaZero, Rio de Janeiro, v. 11, n. 2, sem paginação, abr. 2010.

OTLET, P. Tratado de documentação: o livro sobre o livro teoria e prática. Brasília: Briquet de Lemos / Livros, 2018.

RABELLO, R. A dimensão categórica do documento na Ciência da Informação. Encontros Bibli, Florianópolis, v. 16, n. 31, p. 131-156, 2011. 
ROJAS, R. M. A. Bases teóricas y filosóficas de la bibliotecologia. 2. ed. México: Unam, 2005.

SAGREDO FERNÁNDEZ, F.; IZQUIERDO ARROYO, J. M. Reflexiones sobre "documento": palavra/objeto. Boletín Millares Carlo, [s. l.], n. 5, p. 161197, 1982.

SALDANHA, G. O documento e a "via simbólica": sob a tensão da "neodocumentação". Informação Arquivística, Rio de Janeiro, v. 2, n. 1, p. 6588, jan./jun. 2013.

SALDANHA, L. V. Frevendo no Recife: a música popular urbana do Recife e sua consolidação através do Rádio. 2008. Tese (Doutorado em Música) Instituto de Artes, Universidade Estadual de Campinas, Campinas, 2008.

SOUZA, W. E. R. de; CRIPPA, G. O Patrimônio como processo: uma ideia que supera a oposição material-imaterial. Em Questão, Porto Alegre, v. 17, n. 2, p. 237-251, jul./dez. 2011.

TELES, J. $\mathbf{O}$ frevo rumo à modernidade. Recife: Fundação de Cultura Cidade do Recife, 2008.

UNIVERSIDADE FEDERAL DE PERNAMBUCO. Memorial Denis

Bernardes. Recife: UFPE, 2019.

\title{
Re-signification of the memory of the city of Recife in the frevo lyrics of the conductor Nelson Ferreira
}

\begin{abstract}
This paper approaches the lyrics of frevo music as a document and it studies its relation with social and affective memory; therefore, it's an exploratory and documentary research, whose main objective was to consider, from the frevo lyrics of the maestro pernambucano Nelson Ferreira, the relevance of the musical information for the reconstitution of Recife's memory. To do so, we established as the corpus the musician's songs and lyrics, recorded in two collections of the extinct Rozenblit records factory: $O$ que eu fiz e você gostou... from 1959 and $O$ que faltou e você pediu... from 1968, adopting the qualitative evaluation of Content Analysis method. Thus, the 39 frevos demonstrated, through four thematic categories, that the lyrics are a product of their time, but that they are also a product of the point of view and experience of a man in his time. This experience was then massified through the phenomenon of reproducibility of information and it was perpetuated for almost 100 years, repeating itself through the narratives of the songs that activate this memory when reproduced, bringing it into the present and diluting the individual memory, creating sound links.
\end{abstract}


Keywords: Information Science. Social memory. Affective memory. Place of memory. Frevo.

Recebido: 29/01/2019

Aceito: 15/03/2019

${ }^{1}$ HAYLES, N. K. Translating media: why we should rethink textuality. The Yale Journal of Criticism, Baltimore, v. 16, n. 2, p. 263-290, 2003. Apud Lund (2009).

${ }^{2}$ OCAMPO, L. T. R. Curso de Mestrado em Administração de Centros Culturais: esquema conceitual. Apontamentos Memória \& Cultura, Rio de Janeiro, v. 2, n.1, p. 1-8, 1991. Apud Dodebei (2011). 